HELMINTHOLOGIA, 56, 2: 157 - 167, 2019

\title{
First report on mermithid parasitism (Enoplea: Mermithidae) in a Southeast Asian spider (Araneae: Araneidae)
}

\author{
O. KOŠULIČ' \\ 'Department of Forest Protection and Wildlife Management, Faculty of Forestry and Wood Technology, \\ Mendel University in Brno, Zemědělská 3, Brno 613 00, Czech Republic; ${ }^{2 \star}$ Department of Botany and Zoology, Faculty of Science, \\ Masaryk University, Kotlárská 2, Brno 611 37, Czech Republic, E-mail: masova.sarka@gmail.com
}

Article info

Received February 1, 2019

Accepted February 14, 2019

\section{Summary}

Details about the record of a juvenile mermithid roundworm parasitizing the bark spider Caerostris sumatrana Strand, 1915 from Thailand are presented. The morphology and ecology of both organisms is discussed. Morphological features suggest this juvenile nematode belongs to the genus $\mathrm{cf}$. Aranimermis. Due to the subadult stage of parasite, identification to species-level was not possible. This first report of a nematode infection in $C$. sumatrana with several recent findings from other studies significantly adds to the current inventory of mermithids parasitizing spiders. Moreover, our finding is among the first record of this host-parasite interaction from Southeast Asia.

Keywords: Agamomermis; Aranimermis; Caerostris sumatrana; orb-web spider; parasitoid; Thailand

\section{Introduction}

Spiders are top-predators in arthropod communities playing an important role in insect reduction (Marc et al., 1999; Michalko \& Pekár, 2015; Michalko et al., 2019). However, there are many groups of invertebrates that also feed on spiders. In this respect, parasites and parasitoids are among the very important group of natural enemies of spiders. Recently, records of the parasites and parasitoids of spiders are becoming more frequent and many authors have described occurrences of parasitisation by hymenopterous, dipterous, and neuropterous parasitoids (e.g. Allard \& Robertson, 2003; Finch, 2005; Takasuka et al., 2017). However, very little is known about the relevance of nematode parasitism in spiders (Poinar, 1987; Penney \& Bennett, 2006). These findings are rare and the parasite is usually not identified to species or even genus due to the difficulties in identification which require fully mature adult specimens (Poinar, 1987; Penney \& Bennett, 2006). All of known reports of natural nematode parasitism in spiders belong to the group of parasitoids from the family Mermithidae (order Mermithida), which generally parasitize on invertebrates only (Poi- nar, 1987; Meyer, 2014). Apart from spiders, mermithids can also be found parasitizing in mosquitoes, grasshoppers, butterflies, damselflies or cockroaches (Meyer, 2014). However, for many mermithids, the host species is still unknown (Nickle, 1972).

Up to now, only the following mermithid genera have been recorded to parasite on spiders: Mermis Dujardin, 1845; Hexamermis Steiner, 1924; Agamermis Cobb, Steiner \& Christie, 1923; Heydenius Taylor, 1935 and Arachnomermis Rubtsov, 1978 (Poinar, 1985; Poinar, 2000; Poinar, 2012). Further, Poinar and Welch (1981) erected a collective genus Agamomermis for all identifications based on juvenile material unsuitable for species identification (Poinar, 1987; Allard and Robertson, 2003). Afterwards, Poinar and Benton (1986) and Poinar \& Early (1990) provided the first descriptions based on adult specimens of mermithids and erected the genus Aranimermis with a general characterization of this distinctive genus that is trophically specialized on spiders.

Parasitism by a mermithid is fatal to the host (Nikdel et al., 2011; Poinar, 1983). The life cycle including five stages is described in Poinar (1983): egg, second stage juvenile (preparasitic infective juvenile), parasitic third stage juvenile, mature third stage 


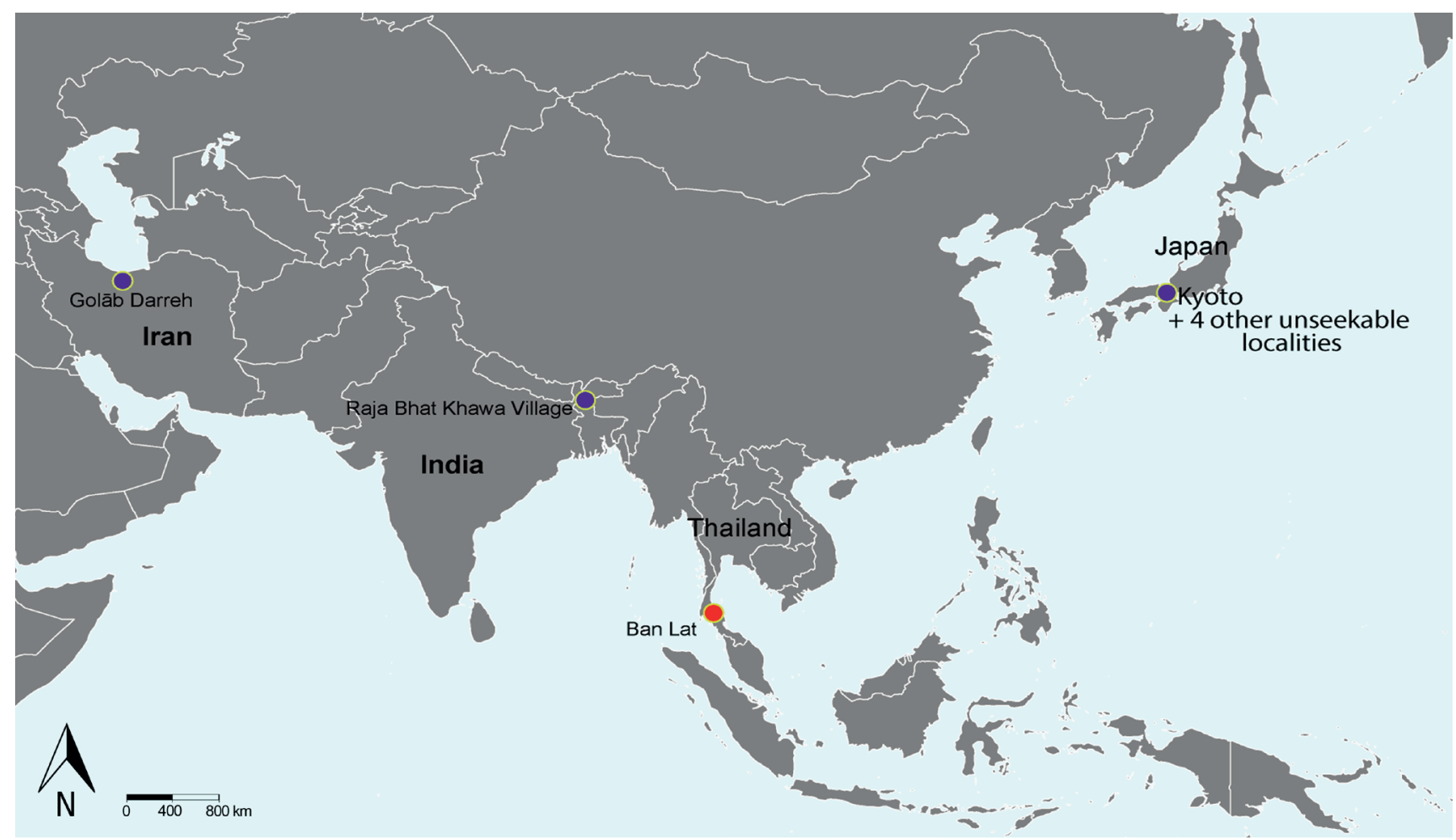

Fig. 1. Distribution map of mermithids parasiting in spiders throughout the whole area of Asia. All seven records (blue circles) from Asia are taken from the following literature: Okochi (1969); Matsuda (1999); lida and Hasegawa (2003); Zamani (2014); Ranade and Prakash (2016). Our finding is marked by red coloured circle (for locality description see Material and Methods).

postparasitic juvenile, two molts into adult. These parasitoids have parenteral intake of nutrition from the host tissues and haemolymph which may strongly influence the physiological condition of the host since the first instars of parasite development (Nikdel et al., 2011). Afterwards, during the emergence of the (still juvenile) parasite, the mermithid nematode kills its host (Poinar, 1987). In this postparasitic free-living stage, the parasite does not feed anymore and only needs a suitable habitat to mature.

Spiders from a variety of functional guilds can be infected with mermithids. An important factor for the completion of these nematodes' life cycle is the presence of water, wet soil, or mud where they can mature after emergence from the spider host (Poinar, 1987; Meyer, 2014). Regardless, the ground dwelling and active hunter spiders are parasitized more often in comparison with orb web or space web spiders (e.g. Penney \& Bennett, 2006; Zamani, 2014). Usually, spiders become infected by ingesting a paratenic host or directly by being penetrated by an infective larva that has recently hatched out from eggs (Penney \& Bennett, 2006). Infected spiders may show symptoms such as an enlarged and deformed abdomen, deformed copulation structures, or deformed legs. Moreover, they may show changes in behaviour such as lethargy, slower reaction times to predators, and a tendency to move towards water (Poinar, 1985; Pizzi, 2009; Meyer, 2014).

The purpose of the present paper is to report the first finding of a mermithid nematode, which parasites in the Caerostris suma- trana Strand, 1915 from the region of Southeast Asia along with ecological notes on the distributions of spider mermithids. To date, there are no records of endoparasitism by nematodes in orb-web spiders from the Asian region and furthermore, there are not even reports of mermithids in any groups of spiders from Southeast Asia. The postparasitic juvenile stage is described and its characteristics are illustrated. The list of records of mermithid infections made by Poinar (1987) and Penney \& Bennett (2006) is updated according to the recent findings (Rodrigues et al., 2005; Meyer, 2014; Zamani, 2014; Ranade \& Prakash, 2016) and amended with the location and region of the host-parasite finding.

\section{Materials and methods}

The two Caerostris spiders were collected on the edge of a dry evergreen forest in the Phethaburi province of Ban Lat district in the central part of Thailand $\left(12^{\circ} 96^{\prime} 85^{\prime \prime} \mathrm{N}, 99^{\circ} 66^{\prime} 53^{\prime \prime} \mathrm{E}\right.$; Fig. 1). The hilly landscape area of the locality was at an altitude of 300-400 m a.s.l. The area from which the parasitized spider was collected was sheltered by a dense canopy of dry evergreen forest with presence of river streams and small patches of disturbed and logged forest stands. Spiders were sampled during rainy season (July 2014), thus the environment in the location was very humid and influenced by short-term heavy rains. Specimens were collected at night by visually searching and removing individuals directly from 





妾

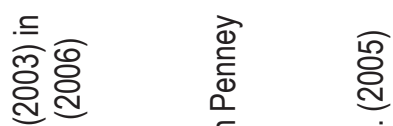

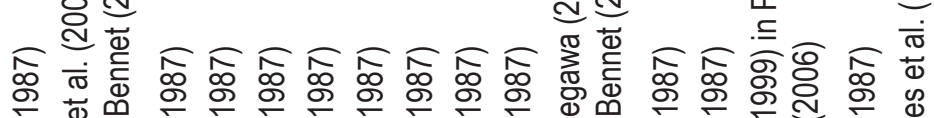

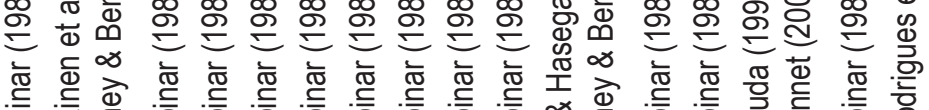

市 .



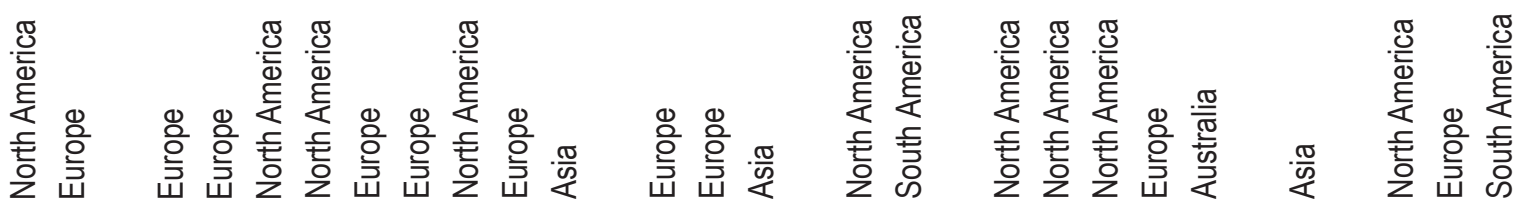

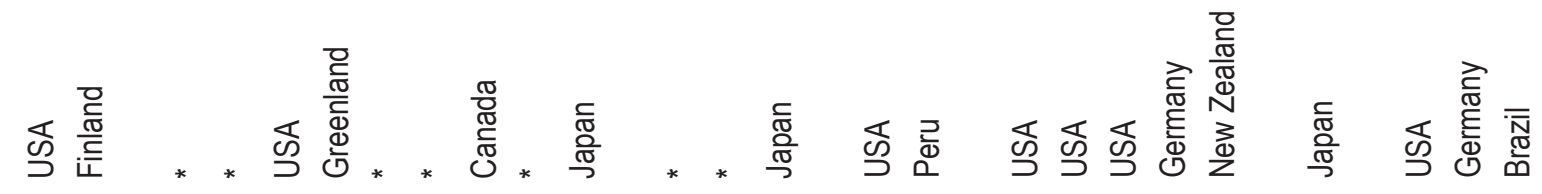



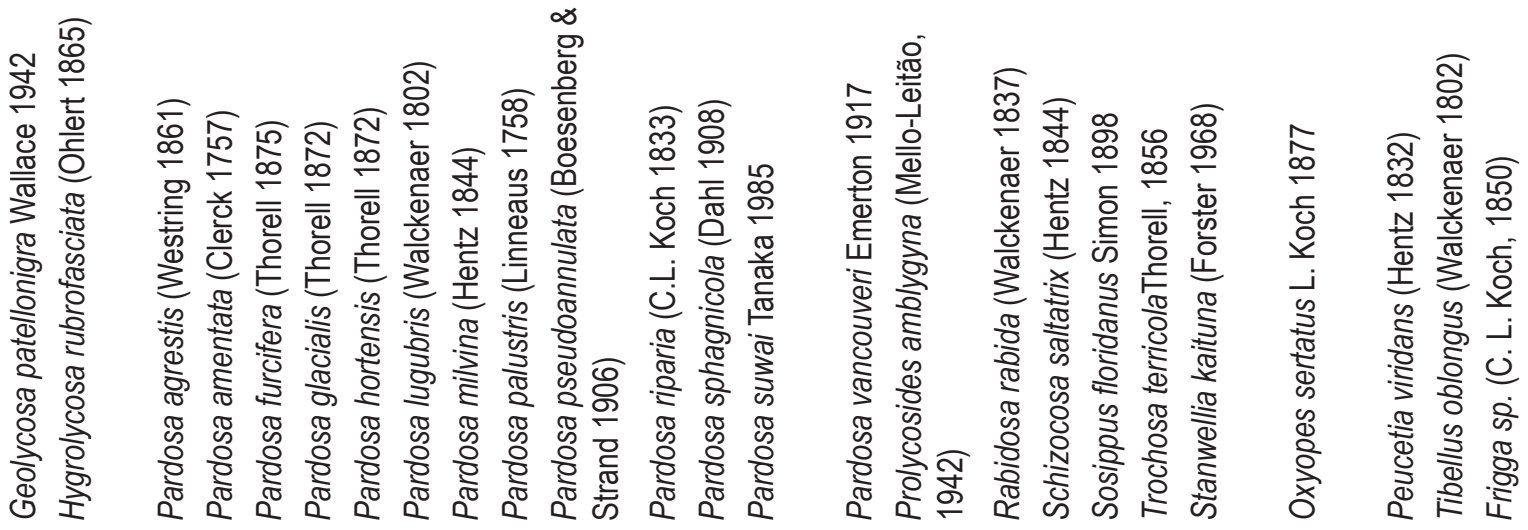

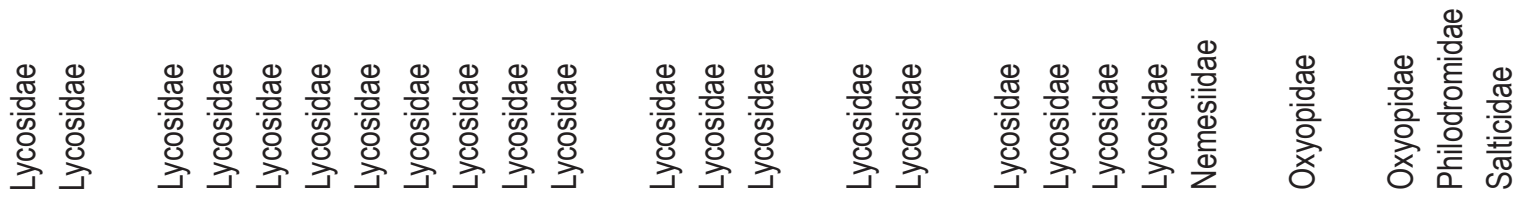




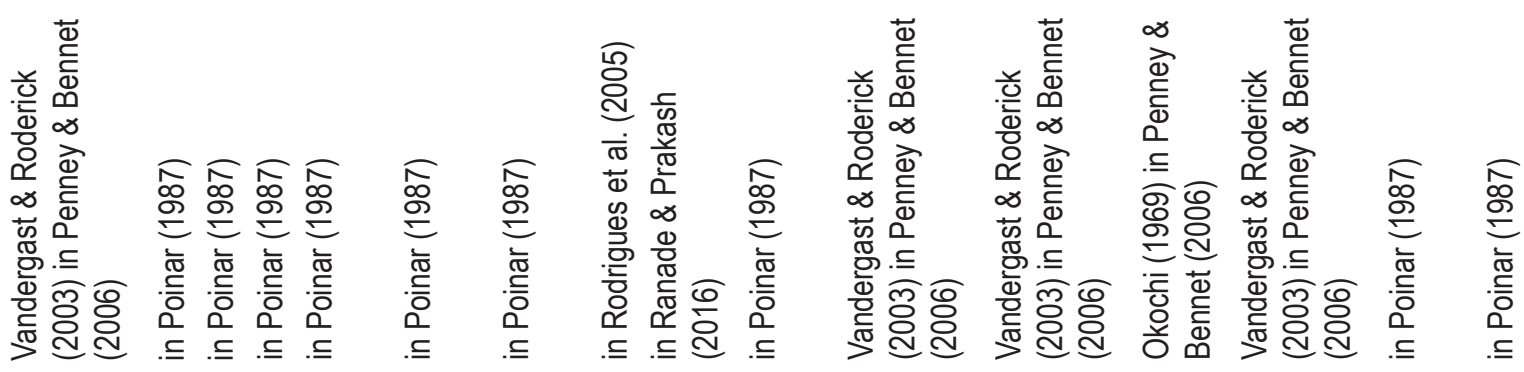

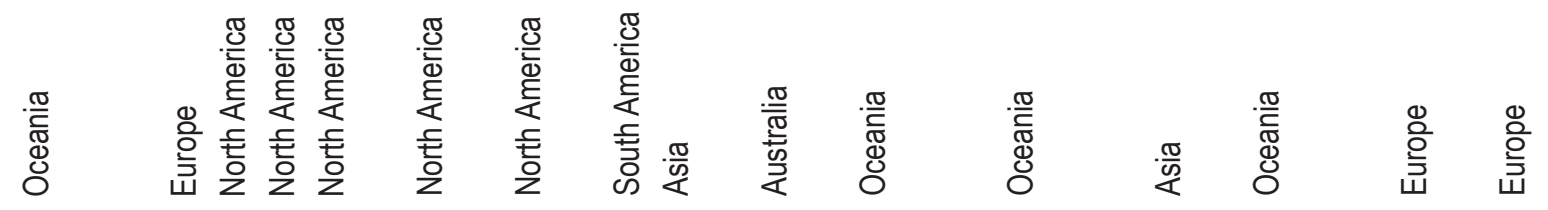

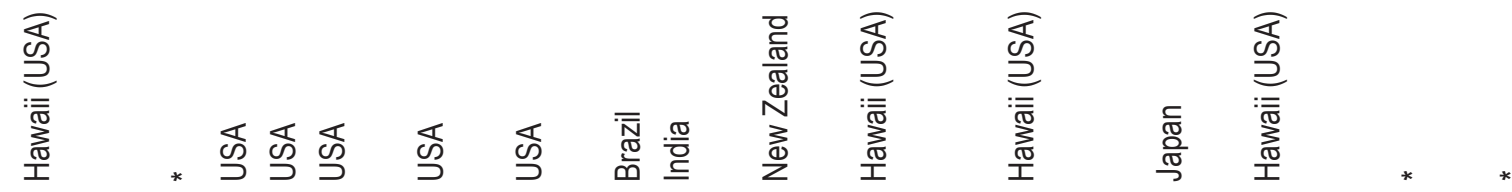

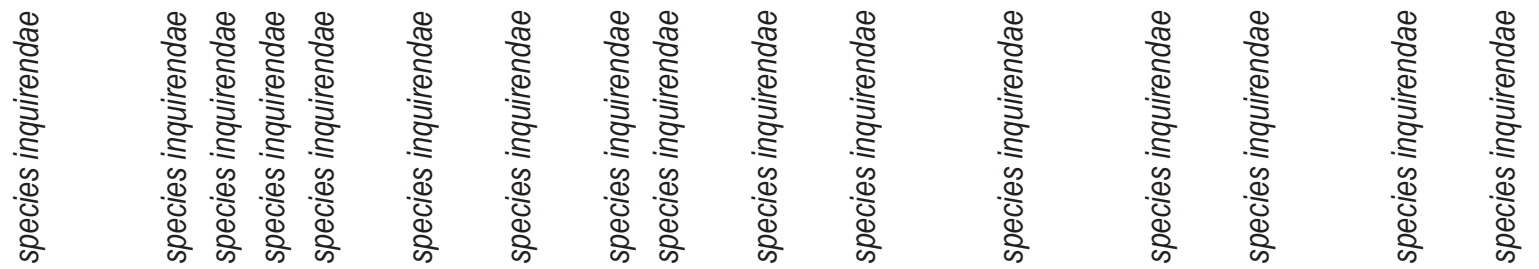

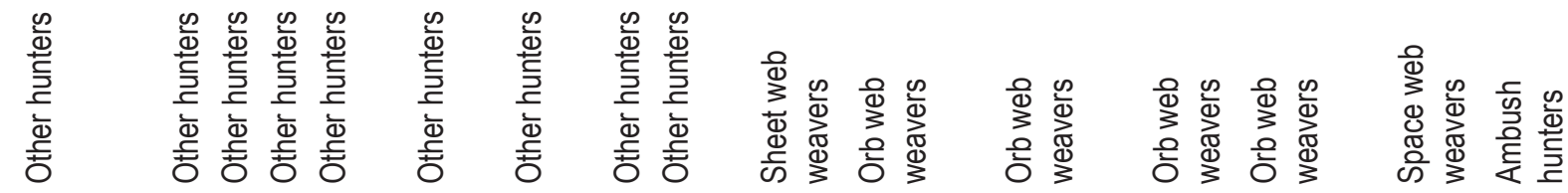



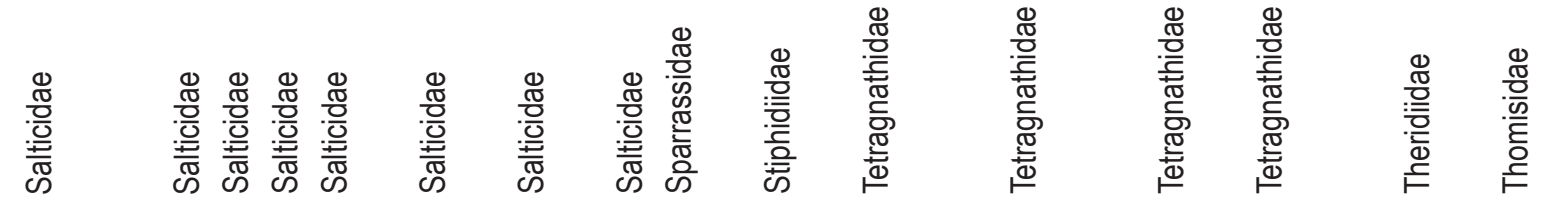




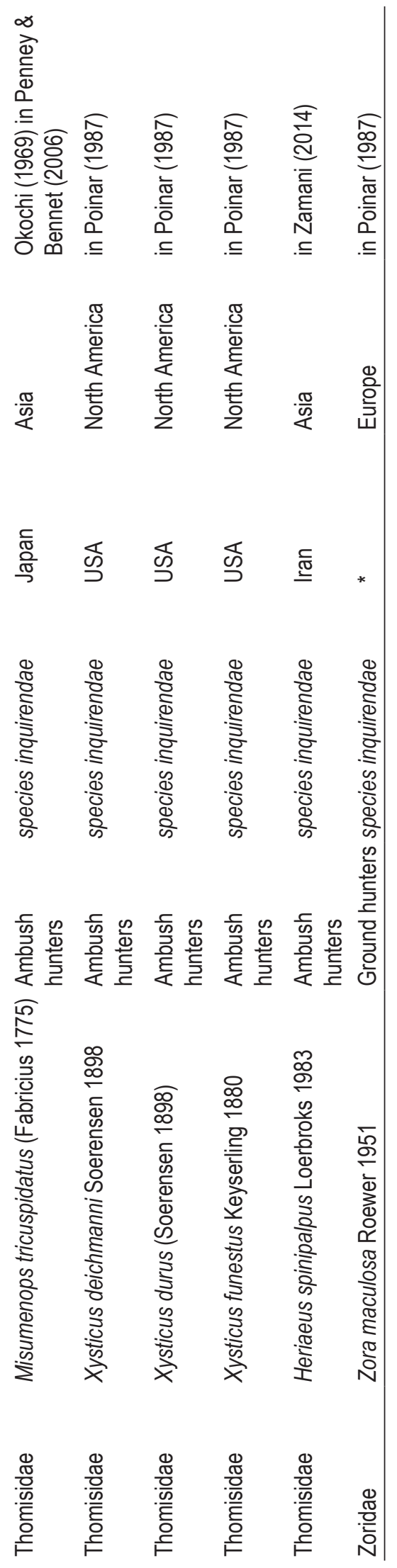



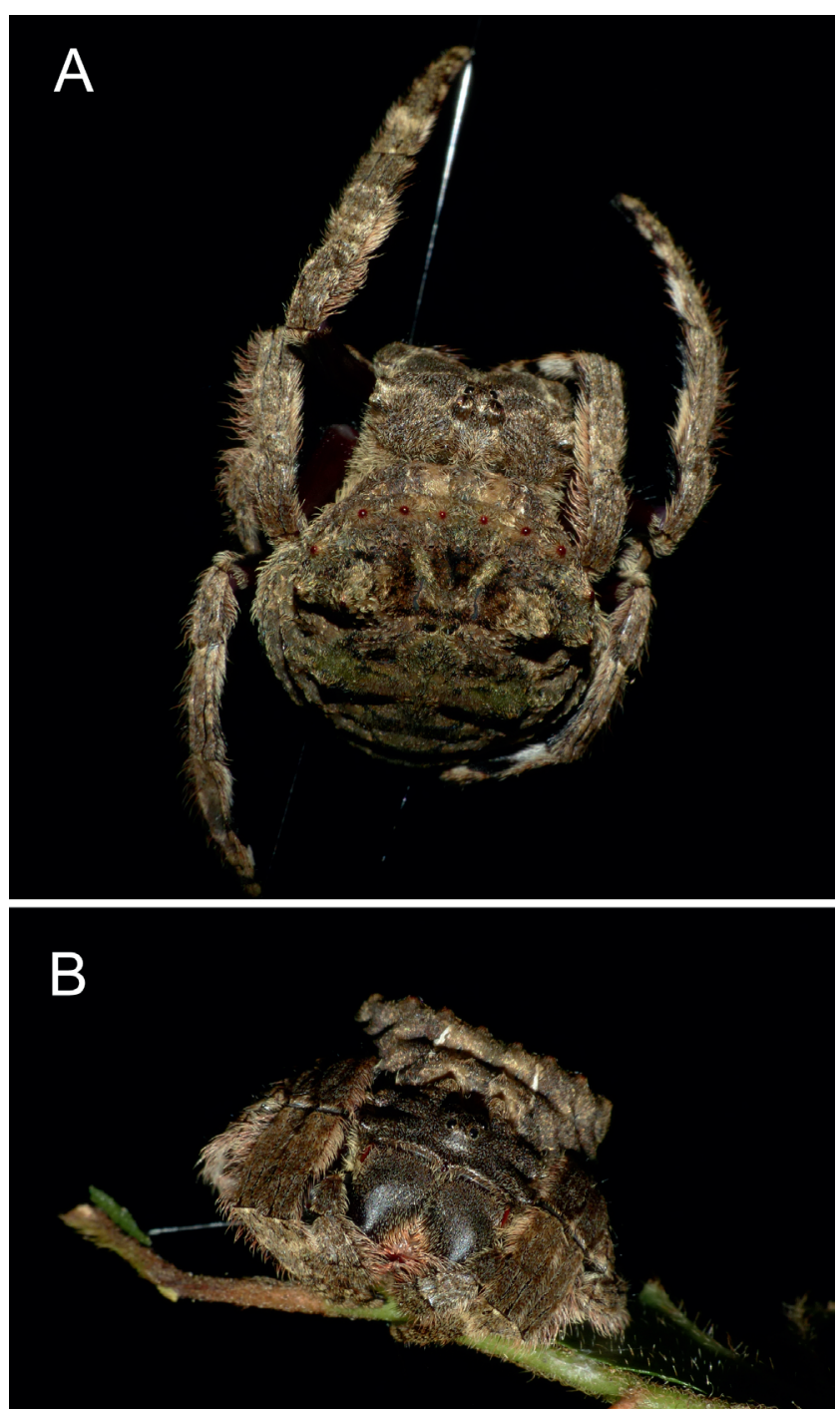

Fig. 2. The parasited spider Caerostris sumatrana in an orb-web before collecting. A: Overal view of spider body without any visible deformations caused by its parasitoid. B: Front view of the same specimen.

the round web. Both females were identified according to available literature (Murphy \& Murphy, 2000) as orb-web spiders, Caerostris sumatrana. After collection, the obtained material was kept alive in $60 \mathrm{ml}$ individual plastic jars.

Parasite emergence from the host started after eight hours of live spider captivity. No freeliving post-parasites were found. After hatching the post-parasitic juvenile as well as the dead spider host were fixed in $70 \%$ ethanol. For light microscopy examination the nematode was transferred gradually into solution of glycerine and water (2:1) before mounting on microscope slides. The examination of the parasite was performed by using an Olympus BX 50 microscope equipped with differential interference contrast (DIC) optics, digital image analysis system (Motion Stream), and a drawing attachment. Graphic processing of images were maintained and modified in Adobe Illustrator CS3 and Photoshop CS4.
The spider and the mermithid nematode have been both deposited in the collection of the Faculty of Forestry and Wood Technology of Mendel University in Brno (voucher number Mendelu-FF-1545).

\section{Ethical Approval and/or Informed Consent}

The conducted research is not related to either human or animals use. Informed consent has been obtained from all individuals included in this study.

\section{Results}

In total, two adult females of $C$. sumatrana (Fig. 2A, B) were found at the locality and were found very close to each other (15 metres). No significant differences in body size or the constitution of both spider samples were found (total length $15.3 \mathrm{~mm}$, opisthosoma $6.2 \mathrm{~mm}$ long and $5.1 \mathrm{~mm}$ wide). One sample of $C$. sumatrana was infected by a nematode which emerged from the host after eight hours of the spider being kept in captivity in a $60 \mathrm{ml}$ plastic jar. Second specimen of spider was kept in captivity for several weeks and no parasitism evidence was found. Therefore, only one specimen of postparasitic juvenile was obtained and measured.

The specimen was brownish in colour (Fig. 3), slightly transparent at the tapered rounded ends (Fig. 4). The mermithid was extremely long in respect to its spider host, it was $28.1 \mathrm{~cm}$ in length and a maximum of $1.2 \mathrm{~mm}$ wide. It was determined as a collective genus Agamomermis Poinar et Welch, 1981, because identification to species level based on such juvenile stage was not possible. However, the morphological features of the examined post parasitic juvenile, including the presence of six cephalic papillae in one plane, amphids located near the lateral cephalic papillae, terminal mouth opening, the lack of lateral lip papillae, and the pointed appendage at the end of the tail (Fig. 4-5), were consistent with those of post parasitic juveniles from the genus Aranimermis Poinar \& Beton, 1986, a species specialized on parasiting in spiders. Based on these charactecters, the specimen was classified as genus cf. Aranimermis.

\section{Discussion}

Spider mermithids are recorded from various parts of the world (Poinar, 1987; Penney \& Bennet, 2006; Zamani, 2014), however their findings are usually rare comprising mainly juvenile specimens ineligible for species designations. This is because of their complex life style and development which in natural conditions usually enables only accidental discoveries (Poinar, 1985). In general, there are two ways in which the spider parasiting mermithids can develope: (i) direct life cycle, that includes the direct penetration of the parasite into the host and (ii) the indirect life cycle in which the mermithid enters the body of the spider by infestation of a paratenic host which are most often larvae of various aquatic insects (Poinar \& Early, 1990; Zamani, 2014). After the emergence 

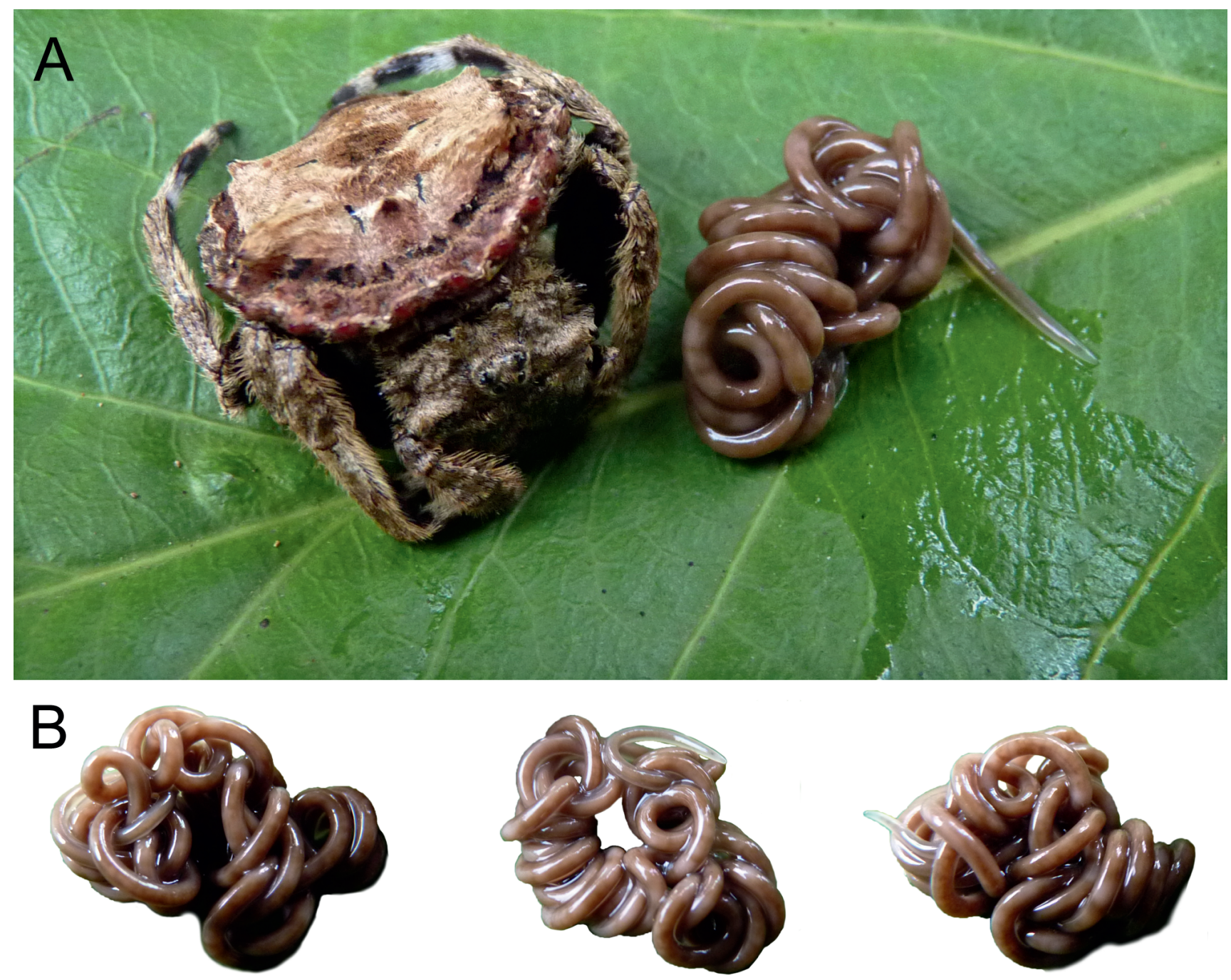

Fig. 3. The host Caerostris sumatrana Strand, 1915 and the live postparasitic juvenile mermithid.

A: Nematode and its killed host after emerging. B: Different positions of the mermithid in motion.

from their host, postparasitic juvenile mermithids needs to mature in soil or freshwater (Poinar \& Early, 1990). Most of the records are provided from this life stage (individuals directly emerging from the spiders), therefore these specimens lack species characteristics and it is only possible to identify them to the family or genus level. According to Poinar \& Welch (1981), the juvenile specimens can only be identified to a collective genus, Agamomermis. However, Poinar \& Benton (1986) raised a new genus, Aranimermis, which includes large and massive species that are specialized on parasitizing in spiders and share the same genus characteristics as our studied sample.

Due to the largeness of some mermithids, parasited spiders often show external morphological abnormalities (Poinar, 1983), e.g. greatly enlarged opisthosoma, an altered epigynum, malformed palpi, shorter and thicker legs, and poorly developed or absent male secondary sexual characteristics (Holm, 1941; Leech, 1966).
Nevertheless, our host did not have any visible changes and it looked the same as the other non-infected specimen which was also collected. Meyer (2004) and Rodrigues et al. (2005) report that infected spiders did not pose any significant changes in morphology, except for swollen abdomens. Therefore, the absence of any significant morphological changes in our sampled spiders (infected and uninfected) is very surprising, especially as the mermithid parasite reached $28 \mathrm{~cm}$ in length. This may be due to the overall massive body-constitution of Caerostris spiders. The spiders in which Poinar (1987) reports abnormalities come from the Lycosidae, Salticidae and Thomisidae families which are much smaller than our Caerostris spider specimen. In our case, internal organs and morphology was not studied, however, we assume severe damage to internal body parts of the spider as the spider specimen died immediately after parasite emergence. In general, the effect of the parasitoid on host physiological appearance re- 


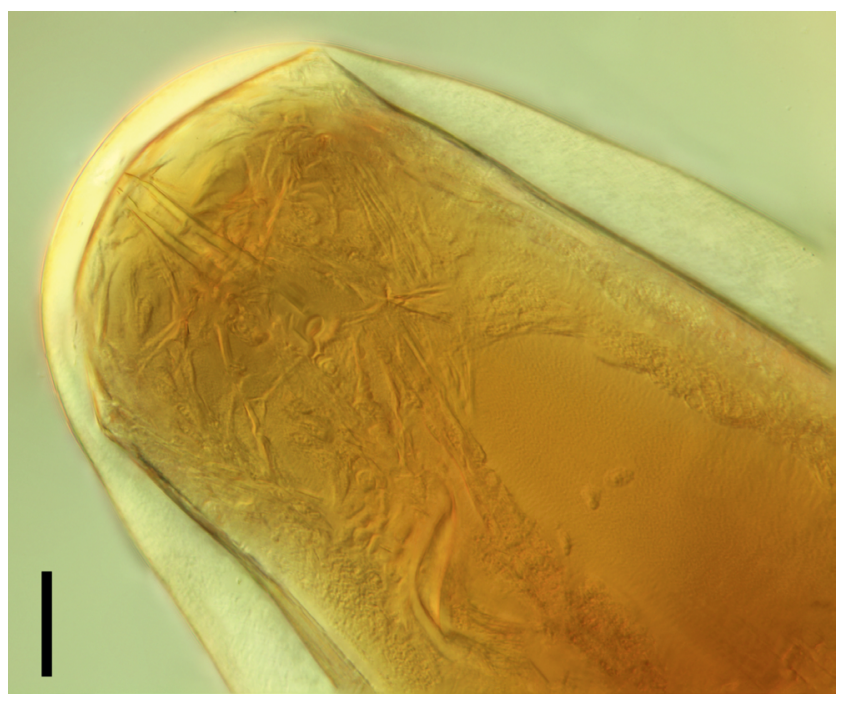

Fig. 4. Light microscopy micrograph (Nomarski contrast, superposition of 11 photos) of the cephalic region of the postparasitic juvenile mermithid from bark spider, Caerostris sumatrana Strand, 1915. Scale bar: $50 \mu \mathrm{m}$.

quires more research before we can fully understand the overall effect of mermithid parasitoids on the spider's body and behaviour. Meyer (2014) points out that the infection rate of spiders by mermithids is higher in spider populations located around habitats suitable for parasite maturation, such as wetlands and freshwater streams, which in addition usually support an increased abundance of aquatic insects which serve as important paratenic hosts.
Indeed, our finding has been conducted near a water stream and during the tropical wet season that is characterized by frequent rainfalls and very high humidity. We suppose that this season is suitable for the final development and maturation of mermithid parasites as the dry season in tropical lowland forests may not be favourable due to the high drought and lower water level in freshwater streams which also is likely to negatively affect paratenic insect hosts (Murphy \& Lugo, 1986). Poinar (1985) point out that most spiders found parasitized would have an opportunity to feed on adult insects which possess an aquatic larval stage. We can support this hypothesis as we have found many prey remains of Trichoptera, Chironomidae and Culicidae in the spider host web. According to Penney \& Bennet (2006) and Meyer (2014) the infection rate in some spider populations may reach more than $8 \%$ and is recorded from all trophic guilds of spiders with different hunting strategies (Cardoso et al. 2011). This is probably because of the indirect development of mermithids that use insects as paratenic hosts, which are the consumed by various hunting guilds of spiders. However, it seems that the highest prevalence of infection has been usually found in actively hunting spiders such as ground and other hunters from Lycosidae and Salticidae families (lida \& Hasegawa 2003; Penney \& Bennet 2006; see updated Table 1). On the other hand, parasitisms in orb-web spiders from Araneidae family, which includes Caerostris sumatrana, are known worldwide only from three species reported to date back more than 30 years ago (Poinar, 1987): Aculepeira ceropegia (Walckenaer 1802), Araneus diadematus Clerck 1757 and Verrucosa arenata (Walcken-



Fig. 5. Line drawings of postparasitic juvenile mermithid from Caerostris sumatrana Strand, 1915.

A: Head region, lateral view. B: Tail region, lateral view. Scale bars: $A=200 \mu \mathrm{m}, B=1 \mathrm{~mm}$ 
aer 1842). No recent documentation has been made for orb-web genus Caerostris, not even for the whole family of Araneidae in last few decades (Penney \& Bennet, 2006).

It must be noted that most of the spider-mermithid interactions come from the Palaearctic and Nearctic region in mild climate of Europe and Northern America (e.g. Penney \& Bennet, 2006; Meyer, 2014). Records from sub-tropical and/or tropical bioregions (especially in Asia) are very scarce and usually only with individual findings (Rodrigues et al., 2005; Zamani, 2014; Ranade \& Prakash, 2016; see Fig. 1). We suppose this could be explained by long-term and constant arachnological research in countries of Europe and/or North America. Furthermore, pitfall trapping is among the most frequent collecting methods for spiders in these regions (Schmidt et al., 2005). This method, usually used with different preservation mediums, efficiently catches high abundances of various groups of epigeic and other actively moving spiders and thus likely enhances the overall chance of catching a mermithid infected spider (see above and Table 1.). On the other hand, arachnological research in Southeast Asian countries has been neglected and very limited, becoming more progressive only in the last 10 years (e.g. Jaeger \& Praxaysombath, 2009, 2011; Wongprom \& Košulič, 2016), therefore we suppose it is the main reason for the lack of records on spider-mermithid interactions from southeast Asia (Fig. 1). This hypothesis is also supported by the increased number of reports on parasitized insects as paratenic hosts for spiders throughout various countries of Southeast Asia during the last couple of decades; therefore this suggests wide distribution of mermithids in insect hosts (e.g. Poinar \& Chang, 1985; Vythilingam et al., 2005; Jitklang et al., 2012).

In conclusion our finding is the first record of a mermithid nematode in the host species of orb-web spiders from the genus Caerostris, and it represents the first evidence of spider-mermithid interactions from Southeast Asia. However, it is very possible that mermithid parasitism is actually widespread in all Asian countries, since a great variety of spiders have been noted as mermithid hosts from other regions (e.g. Poinar, 1985, 1987, 1990; Penney \& Bennett, 2006; Meyer, 2014) and since findings of mermithids in insect paratenic hosts are common throughout southeast Asia (e.g. Jitklang et al., 2012). Unfortunately, the following problems: the low chance of detection in nature, insufficient knowledge of this group, the need for adult stages (especially of males) for identification, and the difficulties in rearing mermithids to the adult stage, all complicate the study of mermithid parasitoids of spiders and their biodiversity in South East Asia and elsewhere.

\section{Conflict of interest}

Authors state no conflict of interest.

\section{Acknowledgments}

We would like to express our thanks to Chaowalit Songsanchote
(Kasetsart University) for the finding of the infected spider and for all of his great kindness and friendship during our stay in Thailand. Further, we would like to thank to Anna Šestáková (Western Slovakia Museum) for confirmation of host species identification. We also thank to anonymous reviewer for his comments and corrections that improved the manuscript. The research was supported in part by European Social Fund and the state budget of the Czech Republic under the project Indicators of Trees Vitality (Reg. No. CZ.1.07/2.3.00/20.0265).

\section{References}

Ahtiainen, J.J., Alatalo R.V., Kortet, R., Rantala, M.J. (2004): Sexual advertisement and immunen function in arachnid species (Lycosidae). Behav. Ecol., 15: 602-606. DOI: 10.1093/beheco/arh062 Allard, C., RoberTson, M.W. (2003): Nematode and dipteran endoparasites of the wolf spider Pardosa milvina (Araneae, Lycosidae). J. Arachnol., 31: 139-141. DOI: 10.1636/0161-8202(2003)031

FINCH, O.D. (2005): The parasitoid complex and parasitoid-induced mortality of spiders (Araneae) in a Central European woodland. J. Natur. Hist., 39: 2339 - 2354. DOI: 10.1080/00222930502005720 HoLm, Å. (1941): Über Gynandromorphismus und Intersexualität bei den Spinnen [Notes on gynandromorphism and intersexuality in spiders]. Zool. Bidr. Uppsala, 20: 397 - 414

IIDA, H., HASEGAWA, H. (2003): First record of a mermithid nematode emerging from the wolf spider Pardosa pseudoannulata (Araneae: Lycosidae). Acta Arachnol., 52: 77 - 78. DOI: 10.2476/asjaa.52.77 Jäger, P., Praxaysombath, B. (2009): Spiders of Laos: New species and new records (Arachnida: Araneae). Acta Arachnol., 58: 27 51. DOI: 10.2476/asjaa.58.27.

Jäger, P., Praxaysombath, B. (2011): Spiders from Laos with forty-three new records and first results from the province Bolikhamsay and Champasak (Arachnidae: Araneae). Acta Arachnol., 60: 9 - 31. 10.2476/asjaa.60.9.

Jitklang, S., Ahantarig, A., Kuvangkadilok, C., Baimal, V., Adler, P.H. (2012): Parasites of larval black flies (Diptera: Simuliidae) in Thailand. Songklanakarin J. Sci. Technol., 34: 6. DOI: 10.2307/3227000 LeECH, R.E. (1966): The spiders (Araneida) of Hazen Camp. Quaest. Entomol., 2: 153 - 212.

MatsudA, M. (1999) Two intersexual spiders of the family Lycosidae from Japan. Bull. Higashi Taisetsu Mus. Natur. Hist., 21: 5 - 54 (In Japanese)

Marc, P., Canard, A., Ysnel, F. (1999): Spiders (Araneae) useful for pest limitation and bioindication. Agric. Ecosyst. Environ., 74: 229 - 273. DOI: 10.1016/S0167-8809(99)00038-9

MEYER, M. (2014): New record of a parasitoid worm (Mermithidae, Nematoda) in a spider of the genus Trochosa (Lycosidae). Arachnol. Mitt., 48: 13 - 15. DOI: 10.5431/aramit4803

Michalko, R., PekÁr, S. (2015): The biocontrol potential of Philodromus (Araneae, Philodromidae) spiders for the suppression of pome fruit orchard pests. Biol. Control, 82: 13 - 20. DOI: 10.1016/j. biocontrol.2014.12.001 
Michalko, R., PekÁr, S., Entling, M.H. (2019): An updated perspective on spiders as generalist predators in biological control. Oecologia, 189: 21 - 36. DOI: 10.1007/s00442-018-4313-1

MurPhy, P.G., Lugo, A.E. (1986): Ecology of tropical dry forest. Annu. Rev. Entomol., 17: 67 - 88. DOI: 10.1146/annurev. es.17.110186.000435

MURPHY, F., MuRPHY, J. (2000): An introduction to the spiders of South East Asia. Malaysia: Malaysian Nature Society, 624 pp.

NICKLE, W.R. (1972): A Contribution to our Knowledge of the Mermithidae (Nematoda). J. Nematol., 4: 113 - 146

Nikdel, M., Kalser, H., Niknam, G. (2011). First record Of Hexamermis cf . albicans (Siebold, 1848) (Nematoda: Mermithidae) infecting Lepidopteran larvae from Iran. Nematol. Mediterr., 39: 81 - 83 Окосні, Т. (1969) Reports on parasites of spiders. Kishidaia, 9: 2 - 5 (In Japanese)

Penney, D., Bennett, S.P. (2006): First Unequivocal Mermithid Linyphiid (Araneae) Parasite - Host Association. J. Arachnol., 34: 273 - 278. DOI: 10.1636/S04-92.1

PIzzı, R. (2009): Parasites of tarantulas (Theraphosidae). J. Exot. Pet Med., 18: 283 - 288. DOI: 10.1053/j.jepm.2009.09.006

Poinar, G.O., WelCH, H.E. (1981) Parasites of invertebrates in the terrestrial environment. In W. SLUSARSKI (Ed) Review of Advances in Parasitology. Warsaw: Polish Scientific Publications, pp. 947 - 954 PoInAR, G.O. (1983): The natural history of Nematodes. Englewood Cliffs: Prentice Hall

PoINAR, G.O. (1985): Mermithid (Nematoda) parasites of spiders and harvestmen. J. Arachnol., 13: 121 - 128

PoInaR, G.O., Chang, P.M. (1985): Hexamermis cathetospiculae n.sp. (Mermithidae, Nematoda), a parasite of the rice stemborer, Tryporyza incertulas (Wlk.) (Pyralidae; Lepidoptera) in Malaysia. J. Nematol., 17: 360 - 363

Polnar, G.O., Benton, C.L.B. (1986): Aranimermis aptispicula n.g., n.sp. (Mermithidae: Nematoda), a parasite of spiders. Syst. Parasitol., 8: 33 - 38. DOI: 10.1007/BF00010307

PoINAR, G.O. (1987): Nematode Parasites of Spiders. In Ecophysiology of Spiders. pp. $299-308$

PoInAR, G.O., EARLY, J.W. (1990): Aranimermis giganteus n. sp. (Mermithidae: Nematoda), a parasite of New Zealand mygalo- morph spiders (Araneae: Arachnida). Rev. Nematol., 13: 403-410 PoInAR, G.O. (2000): Heydenius araneus n.sp (Nematoda: Mermithidae), a parasite of a fossil spider, with an examination of helminths from extant spiders (Arachnida: Araneae). Invertebr. Biol., 119, 388 - 393. DOI: 10.1111/j.1744-7410.2000.tb00108.x Polnar, G.O. (2012): New fossil nematodes in Dominican and Baltic amber. Nematology 14, 483 - 488. DOI: 10.1163/156854111X612199

Ranade, S., Prakash, V. (2016): Parasitization of a huntsman spider (Arachnida: Araneae: Sparassidae: Heteropoda venatoria) by a mermithid nematode (Nematoda: Mermithidae). J. Threat. Taxa, 8: 9595 - 9596. DOI: 10.11609/jott.3105.8.13.9595-9596

Rodrigues, T., Álvares, É.S.S., Machado, É.O., Maria, M. (2005): New records of the family Mermithidae (Nematoda) as parasitoids of spiders (Arachnida: Araneae) in Brazil and Peru. Rev. Iber. Aracnol., 12: 119 - 120

Schmidt, M.H., Clough, Y., Schulz, W., Westphalen, W., TscharntKE, T. (2006): Capture efficiency and preservation attributes of different fluids in pitfall traps. J. Arachnol., 34: 159 - 169. DOI: 10.1636/T04-95.1

Takasuka, K., Korenko, S., Kysilková, K., Štefánik, M., ČerneckÁ, L., MIHÁL, I., DoLEJŠ, P., HoLÝ, K. (2017): Host utilization of koinobiont spider-ectoparasitoids (Ichneumonidae, Ephialtini, Polysphincta genus-group) associated with Cyclosa spp. (Araneae, Araneidae) across the Palaearctic. Zool. Anz., 267: 8 - 14. DOI: 10.1016/j. jcz.2017.01.001

Vythlingam, I., Sidavong, B., Chan, S.T., Phonemixay, T., Phompida, S., KRISHNASAMY, M. (2005): First report of mermithid parasitism (Nematoda: Mermithidae) in mosquitoes (Diptera: Culicidae) from Lao PDR. Trop. Biomed., 22: 77 - 79. DOI: 10.1186/1756-3305$5-131$

WongPRom, P., Košullč, O. (2016): First data on spiders (Arachnida: Araneae) from dry dipterocarp forests of Thailand. Check List, 12: 1 - 13. DOI: 10.1007/s10841-007-9116-3

ZamANI, A. (2014) First report of a mermithid nematode (Enoplea: Mermithida) parasitizing the crab spider Heriaeus spinipalpus (Araneae: Thomisidae). Acta Arachnol., 63: 63 - 64. DOI: 10.2476/ asjaa.63.63 